\title{
Forecasting Cohesionless Soil Highway Slope Displacement Using Modular Neural Network
}

\author{
Yanyan Chen, Shuwei Wang, Ning Chen, \\ Xueqin Long, and Xiru Tang
}

\author{
Transportation Research Center, Beijing University of Technology, Beijing 100124, China \\ Correspondence should be addressed to Shuwei Wang, wangshuwei1010@foxmail.com
}

Received 5 September 2012; Revised 16 November 2012; Accepted 21 November 2012

Academic Editor: Wuhong Wang

Copyright (c) 2012 Yanyan Chen et al. This is an open access article distributed under the Creative Commons Attribution License, which permits unrestricted use, distribution, and reproduction in any medium, provided the original work is properly cited.

The highway slope failures are triggered by the rainfall, namely, to create the disaster. However, forecasting the failure of highway slop is difficult because of nonlinear time dependency and seasonal effects, which affect the slope displacements. Starting from the artificial neural networks (ANNs) since the mid-1990s, an effective means is suggested to judge the stability of slope by forecasting the slope displacement in the future based on the monitoring data. In order to solve the problem of forecasting the highway slope displacement, a displacement time series forecasting model of cohesionless soil highway slope is given firstly, and then modular neural network (MNN) is used to train it. With the randomness of rainfall information, the membership function based on distance measurement is constructed; after that, a fuzzy discrimination method to sample data is adopted to realize online subnets selection to improve the self-adapting ability of artificial neural networks (ANNs). The experiment on the sample data of Beijing city's highway slope demonstrates that this model is superior to others in accuracy and adaptability.

\section{Introduction}

Forecasting the slope displacement accurately in the future becomes a very important step to judge the stability of slope. Forecasting the highway slope displacement in the future is a difficult task which involves evaluation of a large number of interrelated variables and factors and is hardly accounted for a model. Factors affecting slope stability can be divided into two main types: internal factors and external inducements. Internal factors include rock type, joints, property, and structure. External inducements include rainfalls, earthquakes, and human factors. Generally speaking, the slope failures are directly caused by the external inducements, and internal factors are the fundamentals of it. Also, most of these factors have obvious randomness, fuzziness, and variability. All factors interleaving together make the 
influence on the stability of slope, so evaluation criterion which is used to judge the stability of slope should be easily measured and can make clearly manifestations of the change to slope stability.

Displacement is the external expression of deformation process to mass movements of soil and rock. In the past, displacement had been used to compute the prealert, alert, and emergency phases of large rock slides; this method had been validated by collecting and analysing literature data for historical rock slope failures [1]. The forecasting model of slope displacement includes artificial neural networks (ANNs) [2-7], grey theory [8-10], wholeregion method of chaotic time series to slope deformation prediction [11]. The engineering properties of slop exhibit varied and uncertain behaviors, for the complex and imprecise physical processes associated with the formation of soil and rock [12]. So displacement considered as the external expression of slope failure shows evident nonlinear and uncertain characteristics. In order to cope with the complexity of behaviors and the spatial variability of displacement, traditional forms of forecasting models are justifiably simplified. Artificial neural networks (ANNs) refer to a class of artificial intelligence which attempt to mimic the behaviors of the human brain and nervous system, based on the data alone to determine the structure and parameters of the model. It is well suited to complex model problems where the relationship between the model variables is unknown. So, models based on ANNs have been successfully applied on virtually every problem in slope stability. However, rainfalls have important influence on the slop displacement [13-15], the forecasting displacement models of highway slop based on ANNs are focus on the time series variation of displacement, but neglected it.

Modular neural network (MNN) can solve large-scale real-world problems by dividing a problem into smaller and simpler subproblems, assigning a network module to learn each of the subproblems, and recombining the individual modules into a solution to the original problem. In this paper, using rainfall information, the membership function based on distance measurement is constructed, firstly, then a fuzzy discrimination method of sample data is adopted on on-line sub-nets selection in order to improve the self-adapting ability of artificial neural networks (ANNs). The experiment with the sample data of Beijing city's highway slope demonstrates that this model is superior to others in accuracy and adaptability.

\section{Study the Relationship between Displacement and Rainfall}

In order to obtain an accurate forecasting model based on MNN, a theoretical analysis of the relationship between displacement and rainfall has been made. The most common failure mode of cohesionless soil highway slope is landslide, the geological conditions is high permeability weathered layer or slope deposits which covers low hydraulic conductivity rock stratum, and the interface of them is often the potential slip surface. The result of analytic solution from Iverson [16] is used to describe the transient seepage due to rainfall. Then, an elasto-plastic analysis was used to analyze the unstable slope based on Mohr-Coulomb yield criterion and associated flow rule.

Figure 1 shows the force diagram of cohesionless soil highway slope in plane strain condition based on Mohr-Coulomb yield criterion. The assumptions are as follows:

(i) depth of impervious surface and initial groundwater level is denoted by $d$ and $d_{w}$, both of them are parallel to the slope surface; 
(ii) the homogeneous isotropic slide body is elastic-perfectly plastic material, strictly observing the Mohr-Coulomb yield and its flow rule;

(iii) the source of groundwater recharge is only the rainfall; during this process without considering the loss such as evaporation, the soil above the groundwater level is fully saturated soil. In other words, all sliding soil masses have the same weight density (denoted by $\gamma_{\text {sat }}$ );

(iv) ignoring the initial plastic strain of sliding soil mass before raining, at first, the initial effective stress parallel to the slope surface (denoted by $\sigma_{x 0}^{\prime}$ ) is proportional to initial effective stress perpendicular to the slope surface (denoted by $\sigma_{y 0}^{\prime}$ ) and is calculated using

$$
\sigma_{x 0}^{\prime}=k_{0} \sigma_{y 0}^{\prime}
$$

where $k_{0}$ is coefficient of lateral earth pressure. To elastic material, $k_{0}$ can be calculated by poisson ratio (denoted by $\mu$ ) using

$$
k_{0}=\frac{\mu}{1-\mu}
$$

In additional, it is assumed that intensity rainfall has a constant value during the entire process. Based on the analytical solution of Iverson, pore-water pressure with depth $Y$ at time $t$ (denoted by $\phi(Y, t))$ can be calculated by

$$
\begin{gathered}
\phi(Y, t)=\left(Y-d_{w}\right) \cos ^{2} \alpha \\
+2 \frac{I}{K} \sqrt{D_{1} t} \sum_{m=1}^{\infty}\left\{i \operatorname{erfc}\left[\frac{(2 m-1) d-(d-Y)}{2 \sqrt{D_{1} t}}\right]+i \operatorname{erfc}\left[\frac{(2 m-1) d+(d-Y)}{2 \sqrt{D_{1} t}}\right]\right\} \\
-2 \frac{I}{K} H(t-T) \sqrt{D_{1}(t-T)} \sum_{m=1}^{\infty}\left\{i \operatorname { e r f c } \left[\frac{(2 m-1) d-(d-Y)}{\left.2 \sqrt{D_{1}(t-T)}\right]}\right.\right. \\
\left.+i \operatorname{erfc}\left[\frac{(2 m-1) d+(d-Y)}{2 \sqrt{D_{1}(t-T)}}\right]\right\},
\end{gathered}
$$

where $K$ is osmotic coefficient of fully saturated soil, $H(\eta)$ is Heaviside step function, $\alpha$ is slope angle, $D_{0}$ is saturated hydraulic conductivity, and $D_{1}$ can be calculated using

$$
D_{1}=D_{0} \cos 2 \alpha
$$

Function $i \operatorname{erfc}(\eta)$ is given by

$$
i \operatorname{erfc}(\eta)=\frac{1}{\sqrt{\pi}} \exp \left(-\eta^{2}\right)-\eta \operatorname{erfc}(\eta)
$$

where $\operatorname{erfc}(\eta)$ is complementary error function. 


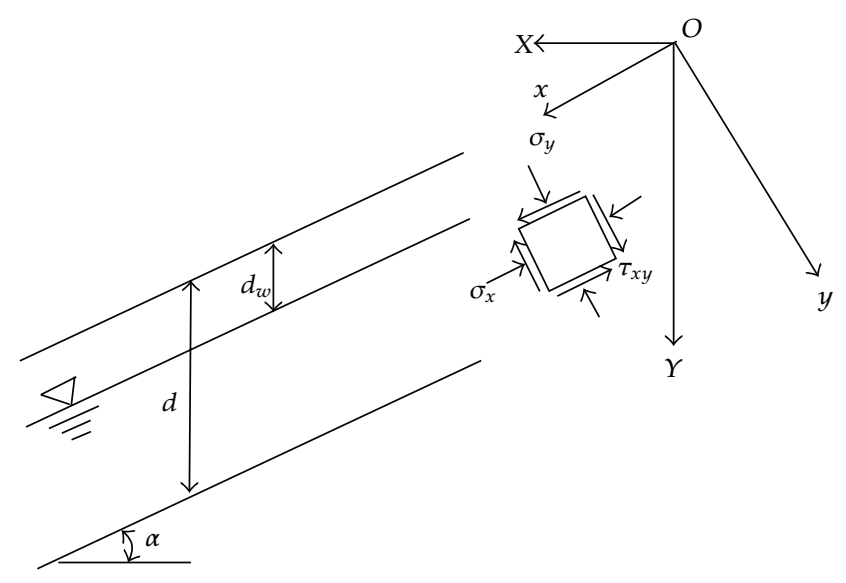

Figure 1: Force diagram of cohesionless soil highway slope.

Otherwise, $\phi(Y, t)$ should meet the requirement of

$$
\phi(Y, t) \leq Y \cos ^{2} \alpha
$$

Hence, the factor of slope safety (defined by $F_{S}$ ) with depth $Y$ at time $t$ can be calculated using

$$
F_{S}(Y, t)=\frac{\tan \varphi^{\prime}}{\tan \alpha}+\frac{c^{\prime}-\phi(Y, t) \gamma_{w} \tan \varphi^{\prime}}{\gamma_{\mathrm{sat}} Y \sin \alpha \cos \alpha}
$$

where $\varphi^{\prime}$ and $c^{\prime}$ are effective angles of internal friction and effective cohesion of soil, and $\gamma_{w}$ is weight density of groundwater.

As shown in Figure 1, total normal stress (denoted by $\sigma_{Y}$ ) and total shear stress (denoted by $\tau_{Y}$ ) with depth $Y$ parallel to the slope surface are calculated using

$$
\begin{gathered}
\sigma_{y}=\gamma_{\text {sat }} Y \cos ^{2} \alpha, \\
\tau_{x y}=\gamma_{\text {sat }} Y \cos \alpha \sin \alpha .
\end{gathered}
$$

Pore-water pressure with depth $Y$ at time $t$ (denoted by $u(Y, t)$ ) can be calculated using (2.9).

$$
u(Y, t)=\phi(Y, t) \gamma_{w}
$$

Effective normal stresses which are parallel to the slope surface (denoted by $\sigma_{x}^{\prime}(Y, t)$ ) and are perpendicular to the slope surfaceare (denoted by $\sigma_{y}^{\prime}(Y, t)$ ) are given by

$$
\begin{gathered}
\sigma_{x}^{\prime}(Y, t)=k_{0} \sigma_{y 0}^{\prime}-\phi(Y, t) \gamma_{w}, \\
\sigma_{y}^{\prime}(Y, t)=\sigma_{y}-\phi(Y, t) \gamma_{w} .
\end{gathered}
$$




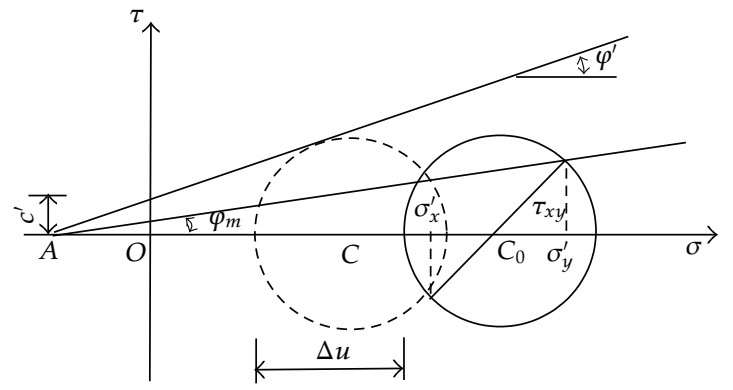

(a) Elastic state

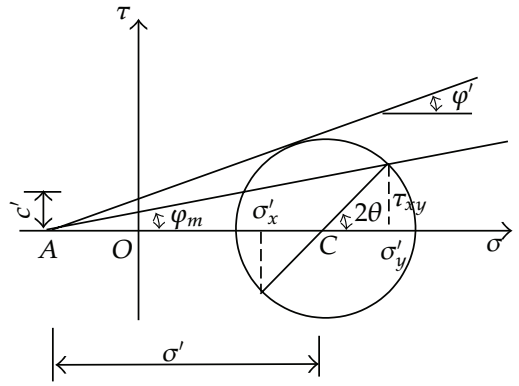

(b) Plastic state

Figure 2: Stress state.

The relationship between Mohr's Circle of Stress and shear strength on site is shown in Figure 2.

Variable $\tan \varphi_{m}$ is defined

$$
\tan \varphi_{m}=\frac{\tau_{x y}}{\sigma_{y}^{\prime}+c^{\prime} \cot \varphi^{\prime}}
$$

As shown in Figure 2(a), (2.12) is satisfied:

$$
\frac{\sqrt{\left(\sigma_{y}^{\prime}-\sigma_{x}^{\prime}\right)^{2}+4 \tau_{x y}^{2}}}{\left(\sigma_{y}^{\prime}+\sigma_{x}^{\prime}\right)+2 c^{\prime} \cot \varphi^{\prime}} \leq \sin \varphi^{\prime} .
$$

Figure 2(a) shows that the increased pore-water pressure after the rainfall will shift the Mohr's Circle of Stress to the left till it is tangent to the curve of shear strength, and it becomes yield at this site, then inequation (2.12) will become equation. However, the yield surface due to yield point does not parallel the bottom plane of slope at this moment (Figure 2(b)); direction of principal stress axis will change with increased pore-water pressure until become parallel to the bottom plane of slope. During this period, stress of plastic zone can be calculated using

$$
\begin{gathered}
\sigma_{x}^{\prime}=\sigma^{\prime}\left(1-\sin \varphi^{\prime} \cos 2 \theta\right)-c^{\prime} \cot \varphi^{\prime}, \\
\sigma_{y}^{\prime}=\sigma^{\prime}\left(1+\sin \varphi^{\prime} \cos 2 \theta\right)-c^{\prime} \cot \varphi^{\prime}, \\
\tau_{x y}=\sigma^{\prime} \sin \varphi^{\prime} \sin 2 \theta,
\end{gathered}
$$

where $\theta$ is the angle of the maximum principal stress from $y$-axis, and it is given as

$$
\tan \varphi_{m}=\frac{\sin \varphi^{\prime} \sin 2 \theta}{1+\sin \varphi^{\prime} \cos 2 \theta}
$$


Under plane strain conditions, Mohr-Coulomb yield criterion can be expressed as $F$, calculated using

$$
F=\sqrt{\frac{1}{4}\left(\sigma_{x}^{\prime}-\sigma_{y}^{\prime}\right)^{2}+\tau_{x y}^{2}}+\frac{1}{2}\left(\sigma_{x}^{\prime}+\sigma_{y}^{\prime}\right) \sin \varphi^{\prime}-c^{\prime} \cos \varphi^{\prime}=0 .
$$

Using the flow rule given by it, strain increment along the critical slip surface has a translational movement, also the value of it is zero, namely, $\mathrm{d} \varepsilon_{x}=0$; the relations between stress and strain increment are taken to be as

$$
\begin{aligned}
& \mathrm{d} \sigma_{x}^{\prime}=M_{12} \mathrm{~d} \varepsilon_{y}+M_{13} \mathrm{~d} \gamma_{x y}, \\
& \mathrm{~d} \sigma_{y}^{\prime}=M_{22} \mathrm{~d} \varepsilon_{y}+M_{23} \mathrm{~d} \gamma_{x y}, \\
& \mathrm{~d} \tau_{x y}=M_{32} \mathrm{~d} \varepsilon_{y}+M_{33} \mathrm{~d} \gamma_{x y},
\end{aligned}
$$

in which

$$
\begin{gathered}
M_{12}=\frac{A B}{D}+\lambda, \\
M_{13}=\frac{C B}{D}, \\
M_{22}=-\frac{B^{2}}{D}+2 G+\lambda, \\
M_{23}=M_{32}=-\frac{C B}{D}, \\
M_{33}=-\frac{C^{2}}{D}+G, \\
A=G \cos 2 \theta+(G+\lambda) \sin \varphi^{\prime}, \\
B=G \cos 2 \theta-(G+\lambda) \sin \varphi^{\prime}, \\
C=G \sin 2 \theta, \\
D=G+(G+\lambda) \sin ^{2} \varphi^{\prime},
\end{gathered}
$$

where $G$ is shear modulus and $\lambda$ is Lame's constants and calculated by using

$$
\lambda=\frac{2 G \mu}{1-2 \mu}
$$


For $\mathrm{d} \sigma_{y}=0, \mathrm{~d} \tau_{x y}=0$, and $\mathrm{d} \sigma_{y}^{\prime}=-\mathrm{d} u$, the displacement of slop can be calculated by using

$$
\begin{gathered}
\mathrm{d} \varepsilon_{y}=-\frac{M_{33}}{M_{32}} \mathrm{~d} \gamma_{x y}, \\
\mathrm{~d} \gamma_{x y}=-\frac{\mathrm{d} u}{G} \frac{\sin 2 \theta\left[\cos 2 \theta-(1+\lambda / G) \sin \varphi^{\prime}\right]}{\left(\cos 2 \theta+\sin \varphi^{\prime}\right)^{2}(1+\lambda / G)} \\
\mathrm{d} \sigma_{x}^{\prime}=\left(-M_{12} \frac{M_{33}}{M_{32}}+M_{13}\right) \mathrm{d} \gamma_{x y} .
\end{gathered}
$$

The slope angle, depth of impervious surface, depth initial groundwater level, weight density of groundwater, the sliding soil mass weight density, coefficient of lateral earth pressure, effective angle of internal friction, saturated hydraulic conductivity, and shear modulus were set up to $\alpha=25^{\circ}, d=4 \mathrm{~m}, d_{w}=4 \mathrm{~m}, \gamma_{w}=9.8 \mathrm{kN} / \mathrm{m}^{3}, \gamma_{\text {sat }}=21.0 \mathrm{kN} / \mathrm{m}^{3}, k_{0}=0.7, \varphi^{\prime}=$ $30^{\circ}, D_{0} \approx 0.001 \mathrm{~m}^{2} / \mathrm{s}$, and $G=2 \mathrm{MPa}$. Also, the coefficient of permeability is expressed as $10^{-4} \mathrm{~m} / \mathrm{s}$ and the upper limit of light rain, moderate rain, heavy rain, heavy rainstorm, severe rainstorm is $1 / K=0.012,0.025,0.05,0.1$, and 0.3 , respectively.

Figure 3 shows the effect of rainfall in slope displacement and the factor of slope safety $\left(F_{s}\right)$ under different rainfall amount. There is an approximate one-to-one correspondence between displacement value and $F_{s}$ with various grades of rainfall; $F_{S}$ is found to decrease markedly with increasing displacement, and the influence of rainfall on the relationship between $F_{s}$ and displacement becomes slight (Figure 3(a)). It needs about 124 hours, 53 hours, 26 hours, 14 hours, and 5 hours to light rain, moderate rain, heavy rain, heavy rainstorm and severe rainstorm to make $10 \mathrm{~mm}$ displacement of slop (Figure 3(b)); so rainfall has a huge impact on the displacement value.

During the calculation of the $F_{S}$, some parameters of model such as physical and mechanical parameters (effective angle of internal friction $\varphi^{\prime}$ and effective cohesion of soil $\left.c^{\prime}\right)$ are uncertain, and they are closely related to test method, soil specimens, reduction factor, and so on. So it is difficult to forecast the displacement of highway slope by this way. Because displacement has an approximate one-to-one correspondence to $F_{s}$, displacement can be used to forecast the failure of highway slop. And rainfall has important influence on the slop displacement; forecasting the displacement of cohesionless soil highway slope in the future with monitoring data based on artificial neural networks (ANNs) should consider the rainfall.

\section{Methods of Study Using Modular Neural Network}

The most feature of ANNs is that they are based on a self-organizing structure that resembles the biological neural system of mammalian brains, and ANNs give an efficient method to solve problems that cannot be exact solved by statistical methods for their theoretical limitations. Thus, displacement forecasting models based on ANNs ignore influence of rainfall, and the values might be unobjective and unconvincing.

MNN uses divide-and-conquer technique, in which a problem is divided into a set of subproblems according to the inherent class relations among training data, then gives a network module to learn each of the subproblems, recombine the individual modules into a solution to the original problem at last. Before learning displacement monitoring data, 


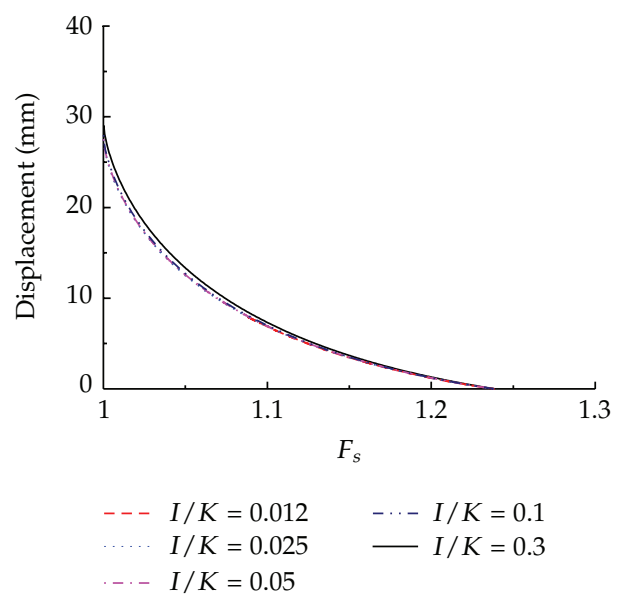

(a) $u-F_{s}$ curve

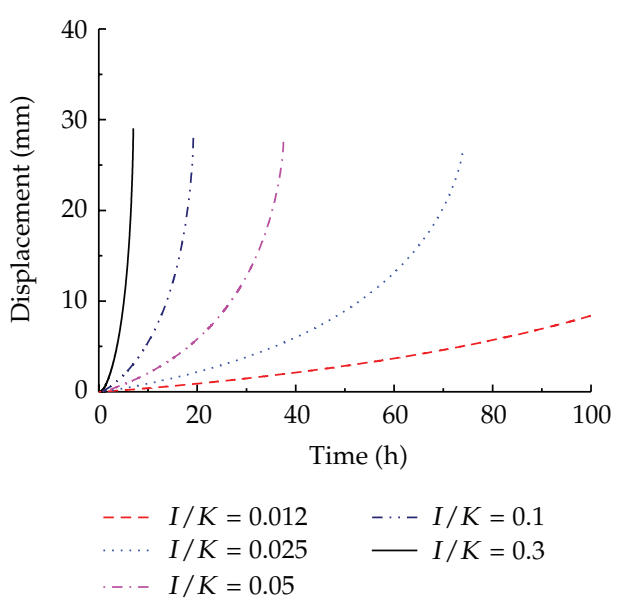

(b) $u-t$ curve

Figure 3: The effect of rainfall on displacement and $F_{s}$.

sample set of slope displacement monitoring data should be correctly classified based on the rainfall grade, after that construct the subnetwork to make the subsample data can be precisely trained, and finally recombine the subnetwork outputs into one. The total output of $\mathrm{MNN}$ is given by

$$
y=\sum_{i=1}^{R} w_{i} y_{i}
$$

where $y$ is the network output, $y_{i}$ is the output of the $i$ th subnetwork (denoted by $\mathrm{NET}_{i}$ ) and $w_{i}$ is the normalized output vector elements of the subnetwork, and $R$ is the number of local networks.

Figure 4 shows the network architecture of the prediction system, which consists of three layers input layer, hidden layer, and output layer, and all of them are completely connected to form a hierarchical network. Subnetworks $\left\{\mathrm{NET}_{1}, \mathrm{NET}_{2}, \ldots, \mathrm{NET}_{R}\right\}$ constitute the network, state of the switches $\left\{E_{1}, E_{2}, \ldots, E_{R}\right\}$ is identified by rainfall, and $R$ is the number of local networks and switches. The sample set of slope displacement monitoring data is defined as $\mathbf{S}=\left\{s_{1}, s_{2}, \ldots, s_{n}\right\}, \mathbf{Z}=\left\{x_{1}, x_{2}, \ldots, x_{n}\right\}$ is the sample set of rainfall, and $n$ is the number of data. $\mathbf{S}$ and $\mathbf{Z}$ have an approximate one-to-one correspondence.

The displacement-time forecasting model is established as (3.2), which allows to forecast the $(t+m)$ th displacement of slope in the future:

$$
s_{t+m}=f\left(s_{t-1}, s_{t-2}, \ldots, s_{t-q}\right),
$$

where $q$ is delay time step.

At first, construct eigenvector for rainfall $x=[\mathrm{LR}, \mathrm{MR}, \mathrm{HR}, \mathrm{TR}, \mathrm{SR}]^{T}$, so that $\mathrm{LR}$ is light rain, $\mathrm{MR}$ is moderate rain, $\mathrm{HR}$ is heavy rain, TR is terrible rainstorm, and $\mathrm{SR}$ is severe 




Figure 4: Modular neural network model.

rainstorm. Consider fuzzy classification of rainfall grade; the displacement monitoring data of sample set $\mathbf{S}$ are classified according to calculation of eigenvector $x$ using

$$
\begin{gathered}
V_{i}=\frac{\sum_{j=1}^{N}\left(u_{i j}\right)^{a} x_{i}}{\sum_{j=1}^{N}\left(u_{i j}\right)^{a}}, \\
v_{i j}=\frac{1}{\sum_{k=1}^{R}\left(\left\|x_{j}-V_{i}\right\| /\left\|x_{j}-V_{d}\right\|\right)^{2 /(b-1)}},
\end{gathered}
$$

where $R$ is the classification number of sample set, $\mathbf{S}=\left\{\mathbf{S}_{1}, \mathbf{S}_{2}, \ldots, \mathbf{S}_{R}\right\}, \mathbf{V}_{i}$ is clustering center of $\mathbf{S}_{i}$, and $\mathbf{v}=\left(v_{i j}\right)$ is the membership matrix of sample to fuzzy subset. In (3.3), $a=1$ and $b=2$ [17]. Some data may simultaneously belong to sample subsets $\mathbf{S}_{i}$ and $\mathbf{S}_{j}$. After that, the back propagation algorithm is used to train the gating and local network $\mathrm{NET}_{i}$ with sample subset $\mathbf{S}_{i}$, and set lower bound on the error $\varepsilon=10^{-8}$ and the maximum iteration number is 2000 [5]. Final results of the MNN can be calculated by (3.1).

To the new test data $s_{f} \notin \mathbf{S}$, the distance measure of $x_{f}$ and $\mathbf{V}=\left[\mathbf{V}_{1}, \mathbf{V}_{2}, \ldots, \mathbf{V}_{R}\right]$ is chosen as criterion to decide which local network it belongs to, calculated using (3.4) and (3.5):

$$
d_{i}=\frac{\left\|x_{f}-V_{i}\right\|}{\overline{d_{i}}}
$$

in which,

$$
\overline{d_{i}}=\frac{1}{n_{i}} \sum_{j=1}^{n_{i}}\left\|x_{j}-V_{i}\right\|
$$

where $d_{i}$ is the relative distance measure of $x_{f}$ and $\mathrm{NET}_{i}, \bar{d}_{i}$ is the average distance measure of $i$ th sample subset, and $n_{i}$ is the number of data for $i$ th sample subset. Displacement monitoring data $s_{f}$ is trained only by local networks in which $d_{i}$ is the smallest one based on 
the traditional MNN it makes the calculation accuracy of boundary samples lower to others. To solve this problem, more than one local network are chosen to training $s_{f}$ with fuzzy decision, in order to significantly enhance the accuracy of MNN model. First, the relative distance measure of $x_{f}$ among all local network normalization can be calculated using

$$
u_{i}=\frac{d_{i}}{\sum_{i=1}^{R} d_{i}} .
$$

In (3.6), $\sum u_{i}=1$ and $u_{i} \in[0,1]$.

Defining fuzzy set of relative distance measure $\mathbf{A}=\{$ very small (denoted by $v s$ ), small (denoted by $s$ ), middling (denoted by $m$ ), large $(l)\}$, the values of $u_{i}$ reflect the distance measure between $x_{f}$ and $\mathrm{NET}_{i}$. If $u_{i} \in\{v s\}$, then local networks $\mathrm{NET}_{i}$ should be used to train $s_{f}$ for the distance of $x_{f}$ and $\mathrm{NET}_{i}$ is short. If $u_{i} \in\{l\}$, then local networks $\mathrm{NET}_{i}$ cannot be used to train $s_{f}$ for the distance of $x_{f}$ and $\mathrm{NET}_{i}$ is long.

The calculation of local networks selection involves the following steps.

Step 1. Calculate $u_{i}$ between every new test data $s_{f} \notin \mathbf{S}$ and its corresponding local networks using (3.4), (3.5), and (3.6).

Step 2. Calculate membership degree of $u_{i}$ to every fuzzy subset A with the membership degree curves as Figure 5 shows.

Step 3. Make a choice which fuzzy subset $u_{i}$ belongs to by the highest membership degree in the fuzzy command, and local networks which belong to the same set are chosen to integrate from $v s$ to 1 . If the local network in which $u_{i} \in\{v s\}$ actually exist, then it should be used to train the data $s_{f}$, otherwise, select local network in which $u_{i} \in\{s\}$, until selecting local network in which $u_{i} \in\{m\}$.

Due to the symmetry of the Gaussian distribution, the center value of membership degree decreases $50 \%$ at each time by adopting Gauss function for fuzzy membership functions. The center of fuzzy subset to membership degree $\{v s, s, m, l\}$ is $0.25 / P, 0.5 / P, 1 / P$, $2 / P$ and the value of membership degree is 1 when $u_{i}<0.25 / P$ or $u_{i}>2 / P$. For $\sum u_{i}=1$, all $u_{i}$ cannot meet $u_{i}>1 / P$ at the same time; meanwhile, the local network corresponding to $u_{i} \in\{v s, s, m\}$ would not be the empty set. The local network corresponding to $u_{i} \in\{l\}$ should not be chosen for selecting sequence of local network is from vs to 1 in Step 3.

The weight of local network that is selected is given by

$$
w_{f i}=\frac{1 / d_{f i}}{\sum_{i=1}^{L} 1 / d_{f i}}
$$

where $w_{f i}$ is the weight of local network that is selected, $d_{f i}$ is the distance measure of $i$ th local network, and $L$ is the number of local networks that has been selected.

\section{Simulation Results}

Hence, in order to illustrate the effectiveness of the model validity, one of Beijing city's highway slopes is chosen for test. Geological investigations in the collapse area in this 


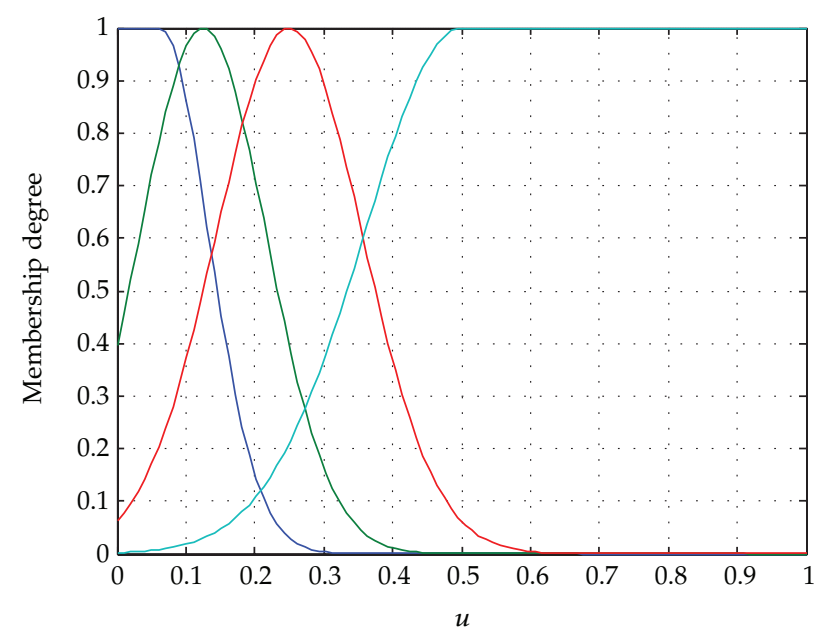

Figure 5: Membership degree curves of $u_{i}$.

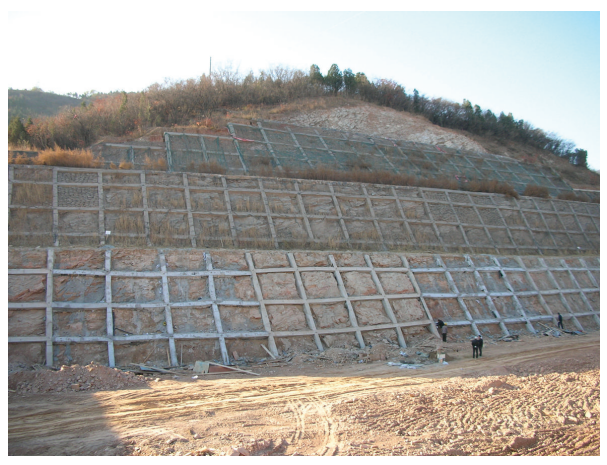

(a)

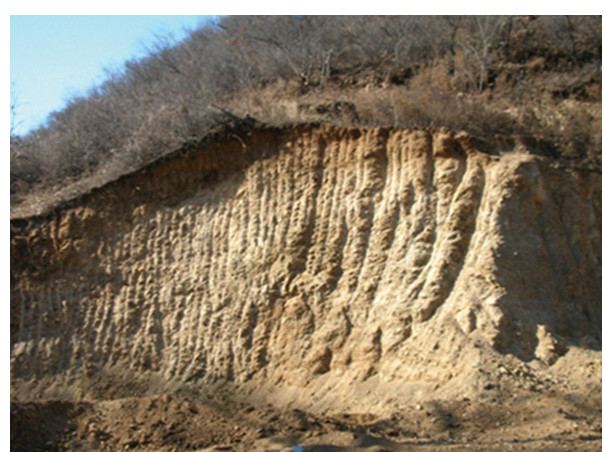

(b)

Figure 6: Location of slope and brief geological descriptions.

research are based on site investigation and the evaluation of remote survey images; the location and brief geological descriptions of slope are shown as Figure 6 .

Time series analysis was used to set up displacement-time forecasting model for both MNN model and ANN model [18]. And then forecast cohesionless soil highway slope displacement in the future based on the same sample data.

Setting model parameters $K=5$ for the classification number of sample set, the number of hidden node in multilayer feedforward neural network that is used to train local networks is 4, and delay time step $q$ which is calculated with autocorrelation method is 6 [19].

Figure 7 shows the relative error for the group of displacement monitoring data that is in the same rainfall grade, namely, ignoring influence of rainfall through selecting the displacement monitoring data in one rainfall grade. And their respective margins of error are almost the same as each other because both of the methods use back propagation algorithm to training.

Displacement data records the state of this cohesionless soil highway slope from the period May 22 to October 31, 2011. Due to the fact that rainfall series is necessary for the 


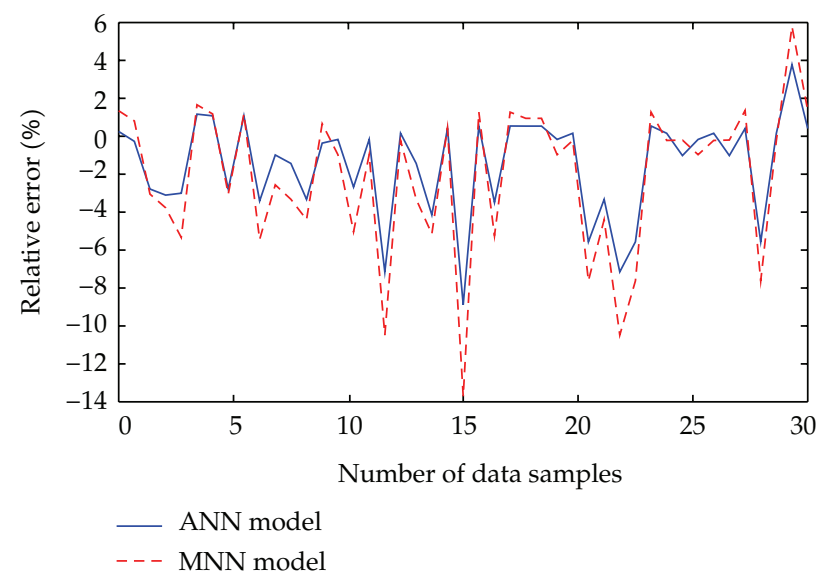

Figure 7: Relative error curve of models.

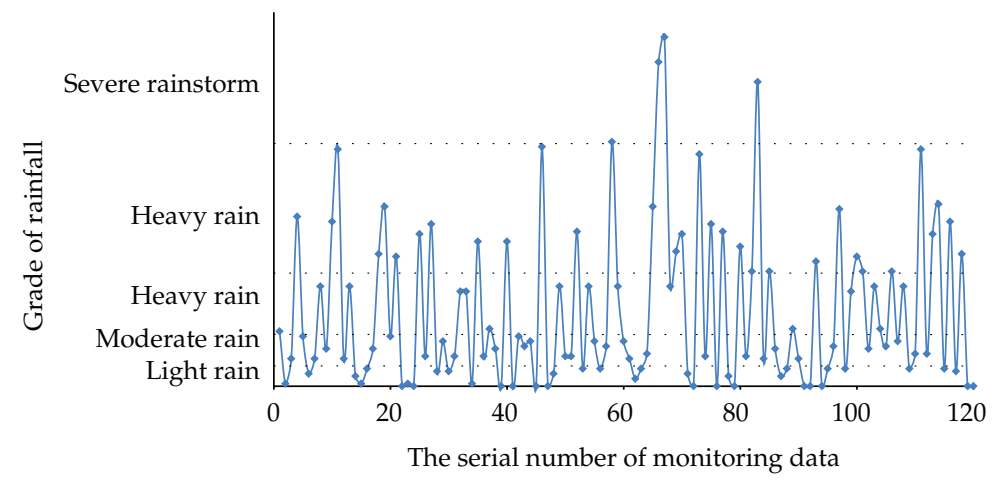

Figure 8: Rainfall distribution map.

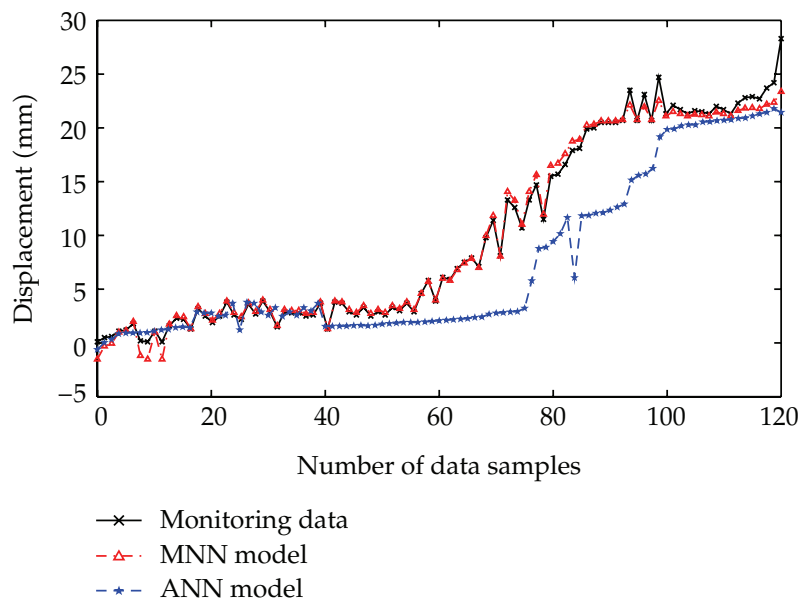

Figure 9: Displacement forecast curves. 


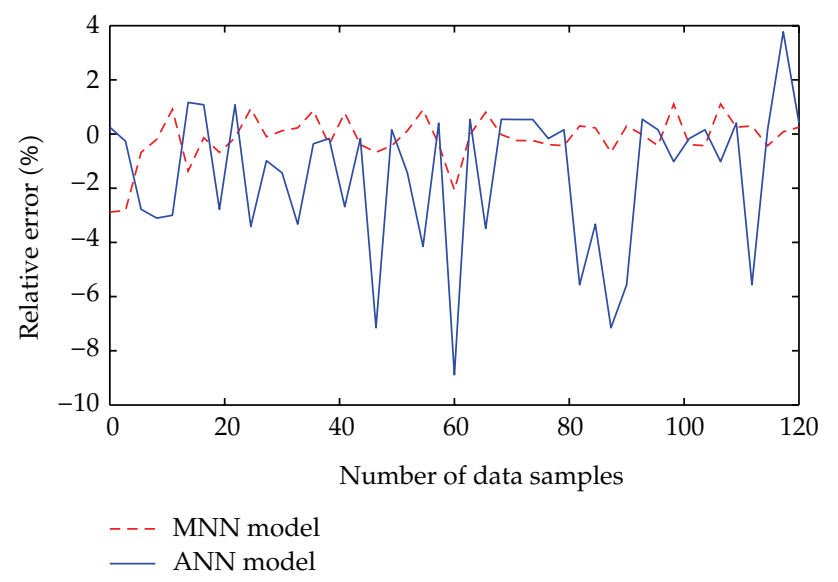

Figure 10: Relative error curve of models.

failure of slope, the meteorological station was built at the slope. Figure 8 shows the grade of rainfall distribution map at precipitation station of highway construction area during the whole observation period.

Figure 9 shows three curves of forecast data based on two methods and the real data during the whole observation period. The forecast data consider the influence of rainfall.

Figure 10 shows their relative error curves of displacement forecast data.

Note that in Figures 9 and 10, MNN offers a highly satisfactory method to forecast the slope displacement, which is better than the ANN model. MNN model has a moderate relative error, but ANN model shows even bigger fluctuations especially after intense rainfall.

The value of mean square error and average relative error of these models under different conditions is just as shown Table 1.

According to the above-mentioned analyses, we can get the results that (1) Whichever algorithm of artificial neural networks is chosen and both models have accurate forecast data of the slope displacement. (2) When considering the influence of rainfall, the fitting situation of MNN model is better than ANN model, mean square error of MNN model is only $7.73 \%$ of ANN model's, and average relative error of MNN model is $27.65 \%$ of ANN model's. (3) When considering the influence of rainfall, both models' errors are sharply decreased, and MNN model performs better than ANN model.

\section{Conclusion}

Displacement monitoring data of highway slop is classified by the MNN based on the same type of data with the same character, which fits the monitoring needed. Also, the method reduces the complexity of the modular neural network and its generalization capabilities could remarkably be enhanced.

When considering the influence of rainfall, the precision of MNN model is much higher than ANN model. The MNN model has a good applicability for the self-learning ability and data-driven ability than ANN model, and it can enhance the applicability of model by retraining the networks with new data at regular intervals. 
Table 1: Accuracy of models.

\begin{tabular}{|c|c|c|c|c|}
\hline \multirow[b]{2}{*}{ Model } & \multicolumn{2}{|c|}{ Ignore influence of rainfall } & \multicolumn{2}{|c|}{ Consider the influence of rainfall } \\
\hline & $\begin{array}{c}\text { Mean square } \\
\text { error/mm }\end{array}$ & $\begin{array}{l}\text { Average } \\
\text { relative error }\end{array}$ & $\begin{array}{c}\text { Mean square } \\
\text { error/mm }\end{array}$ & $\begin{array}{c}\text { Average } \\
\text { relative error }\end{array}$ \\
\hline MNN model & $7.927 \times 10^{-2}$ & $8.25 \%$ & $2.737 \times 10^{-4}$ & $2.06 \%$ \\
\hline ANN model & $8.724 \times 10^{-2}$ & $6.17 \%$ & $3.539 \times 10^{-3}$ & $7.45 \%$ \\
\hline
\end{tabular}

\section{Acknowledgments}

This research was supported by China's Eleventh Five-Year National Science and Technology Support Project (no. 2009BAG13A02) and Science and Technology Project of MOT (no. 2012364223300).

\section{References}

[1] G. B. Crosta and F. Agliardi, "Failure forecast for large rock slides by surface displacement measurements," Canadian Geotechnical Journal, vol. 40, no. 1, pp. 176-191, 2003.

[2] S. H. Ni, P. C. Lu, and C. H. Juang, "A fuzzy neural network approach to evaluation of slope failure potential," Microcomputers in Civil Engineering, vol. 11, no. 1, pp. 59-66, 1996.

[3] S. Lee, J. H. Ryu, K. Min, and J. S. Won, "Landslide susceptibility analysis using GIS and artificial neural network," Earth Surface Processes and Landforms, vol. 28, no. 12, pp. 1361-1376, 2003.

[4] K. M. Neaupane and S. H. Achet, "Use of backpropagation neural network for landslide monitoring: A case study in the higher Himalaya," Engineering Geology, vol. 74, no. 3-4, pp. 213-226, 2004.

[5] H. B. Wang, W. Y. Xu, and R. C. Xu, "Slope stability evaluation using Back Propagation Neural Networks," Engineering Geology, vol. 80, no. 3-4, pp. 302-315, 2005.

[6] L. Ermini, F. Catani, and N. Casagli, "Artificial Neural Networks applied to landslide susceptibility assessment," Geomorphology, vol. 66, no. 1-4, pp. 327-343, 2005.

[7] H. Guo, W. Wang, W. Guo et al., "Reliability analysis of pedestrian safety crossing in urban traffic environment," Safety Science, vol. 50, no. 4, pp. 968-973, 2012.

[8] J. B. Zhao, L. Li, and Q. Gao, "Research and application of the grey theory to slope deformation prediction," Chinese Journal of Rock Mechanics and Engineering, vol. 24, no. 2, pp. 5799-5802, 2005.

[9] D. Wang, M. Zhou, and Y. Li, "Displacement analysis of slope based on wavelet transformation and grey theory," in Proceedings of the International Conference on Electric Technology and Civil Engineering (ICETCE '11), pp. 4929-4932, Lushan, China, April 2011.

[10] W. Wang, Vehicle's Man-Machine Interaction Safety and Driver Assistance, China Communications Press, Beijing, China, 2012.

[11] H. Zhi-quan and F. U. Wen-bin, "The whole-region method of chaotic time series for slope deformation prediction," Journal of North China Institute of Water Conservancy and Hydroelectric Power, vol. 30, no. 3, pp. 70-73, 2009.

[12] M. B. Jaksa, The influence of spatial variability on the geotechnical design properties of a stiff, overconsolidated clay [Ph.D. thesis], The University of Adelaide, Adelaide, Australia, 1995.

[13] T. Glade, M. Crozier, and P. Smith, "Applying probability determination to refine landslidetriggering rainfall thresholds using an empirical "Antecedent Daily Rainfall Model"," Pure and Applied Geophysics, vol. 157, no. 6-8, pp. 1059-1079, 2000.

[14] J. M. Gasmo, H. Rahardjo, and E. C. Leong, "Infiltration effects on stability of a residual soil slope," Computers and Geotechnics, vol. 26, no. 2, pp. 145-165, 2000.

[15] C. Chien-Yuan, C. Tien-Chien, Y. Fan-Chieh, and L. Sheng-Chi, "Analysis of time-varying rainfall infiltration induced landslide," Environmental Geology, vol. 48, no. 4-5, pp. 466-479, 2005.

[16] R. M. Iverson, "Landslide triggering by rain infiltration," Water Resources Research, vol. 36, no. 7, pp. 1897-1910, 2000.

[17] M. G. C. A. Cimino, W. Pedrycz, B. Lazzerini, and F. Marcelloni, “Using multilayer perceptrons as receptive fields in the design of neural networks," Neurocomputing, vol. 72, no. 10-12, pp. 2536-2548, 2009. 
[18] X. Liu, X. H. Zeng, and C. Y. Liu, "Research on artificial neural network-time series analysis of slope nonlinear displacement," Chinese Journal of Rock Mechanics and Engineering, vol. 24, no. 19, pp. 34993504, 2005.

[19] M. T. Rosenstein, J. J. Collins, and C. J. De Luca, “Reconstruction expansion as a geometry-based framework for choosing proper delay times," Physica D, vol. 73, no. 1-2, pp. 82-98, 1994. 




Advances in

Operations Research

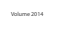

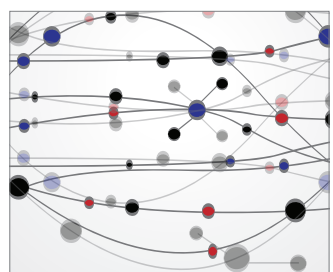

\section{The Scientific} World Journal


International Journal of

Mathematics and

Mathematical

Sciences


Journal of

Applied Mathematics
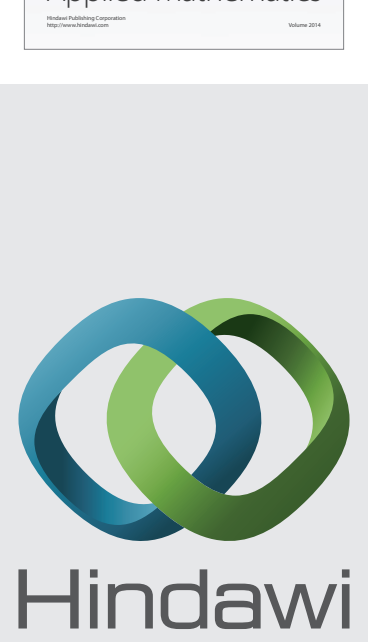

Submit your manuscripts at http://www.hindawi.com
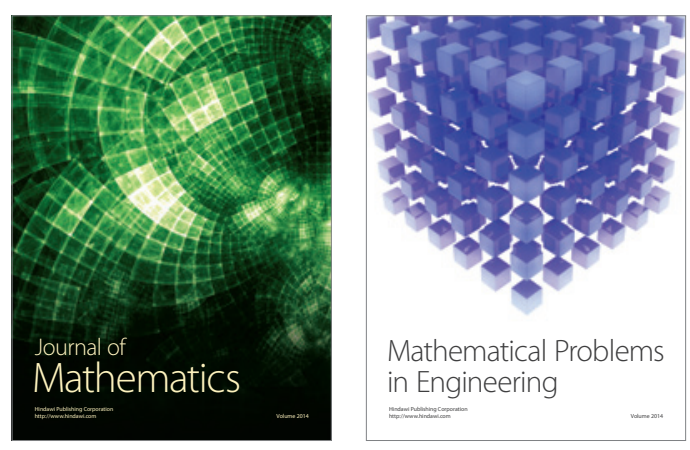

Mathematical Problems in Engineering


Journal of

Function Spaces
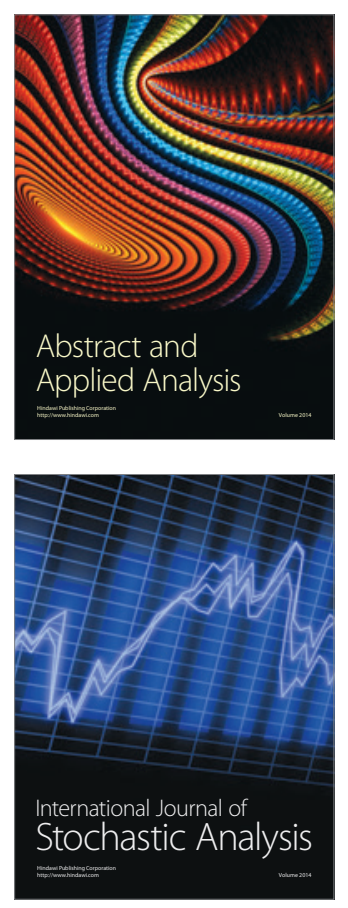

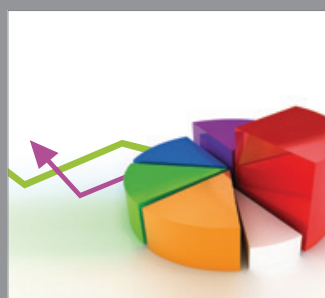

ournal of

Probability and Statistics

Promensencen
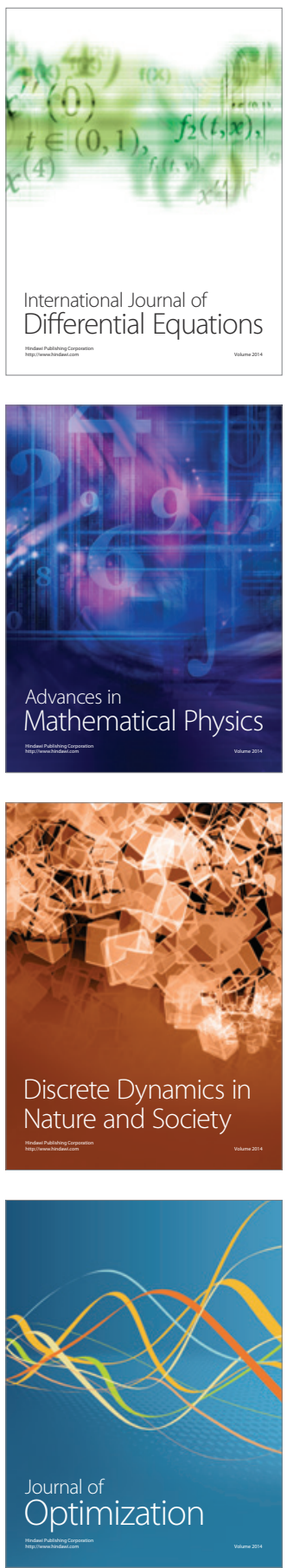